www.jmscr.igmpublication.org Impact Factor 5.244

Index Copernicus Value: 83.27 ISSN (e)-2347-176x ISSN (p) 2455-0450 crossref DOI:_https://dx.doi.org/10.18535/jmscr/v4i11.05

\title{
Prognostic Value of Pulmonary Dead-Space Fraction and other Physiological Parameters in Patients with the Acute Respiratory Distress Syndrome
}

\author{
Authors \\ Osama M Momtaz, MD'; Ali O Abdelaziz, $\mathrm{MD}^{2}$; and Mohamed O Abdelaziz, $\mathbf{M D}^{3}$ \\ ${ }^{1}$ Critical Care Department, Faculty of Medicine, Fayoum University. ${ }^{2}$ Chest Department and ${ }^{3}$ Internal \\ Medicine Department, Faculty of Medicine, El-Minia University, Egypt \\ Corresponding Author \\ Osama M Momtaz, MD \\ Email: usamamomtaz@yahoo.com,Mobile+2/01224274142, +2/01155560083
}

\begin{abstract}
Background: Physiologic dead-space fraction (DSF) (ratio of dead space to tidal volume [VD/VT]) is the portion of tidal volume that does not participate in gas exchange. Newer evidence indicates that VD/VT is markedly elevated within $24 \mathrm{~h}$ of acute respiratory distress syndrome (ARDS) onset and is significantly elevated in non-survivors. Moreover, sustained elevation of VD/VT in ARDS has been associated with higher mortality.

Objectives: to study the physiological dead space fraction and various physiological parameters in mortality prediction for patients with ARDS.

Methods: The study included 30 patients admitted to the ICU with ARDS. All patients were subjected to Full medical history, general examination, arterial blood gases, laboratory investigations, chest imaging, echocardiography and assessment by Acute physiology and chronic health evaluation (APACHE II) and Lung injury scoring. Patients were followed up until ICU discharge or demise. Various physiological parameters including dead space fraction, airway resistance, static and dynamic pulmonary compliance, peak inspiratory pressure and positive end-expiratory pressure were measured.

Results: The overall mortality was $60 \%$. The mean dead-space fraction was significantly higher in patients who died than in those who survived $(0.67 \pm 0.08 \mathrm{vs.} 0.57 \pm 0.09, P<0.001)$ (table 3). The risk of death increased as the dead-space fraction increased. The dead-space fraction was also independently associated with an increased risk of death in the multiple-regression analysis. For every increase of 0.05 in the dead-space fraction, the odds of death increased by 65 percent (odds ratio, 1.65; 95 percent confidence interval, 1.25 - 1.79; P=0.001) (table 4). Decreased both static and dynamic compliance as well as $\mathrm{PaO}_{2} / \mathrm{FiO}_{2}$ were independently associated with unfavorable outcome. The odds of death increased as the APACHE II and Lung injury scores increased and as compliance and $\mathrm{PaO}_{2} / \mathrm{FiO}_{2}$ decreased. The positive end expiratory pressure was not associated with an increased mortality (odds ratio, 1.05; 95 percent confidence interval, 0.95 to 1.19; $P=0.23$ ). There was significant negative correlation between DSF on admission and static compliance $\left(r=-0.43, \mathrm{P}\right.$ value 0.01), dynamic compliance $\left(r=-0.47, \mathrm{P}\right.$ value 0.01)and $\mathrm{PaO}_{2} / \mathrm{FiO}_{2}(r=0.73, \mathrm{P}$ value 0.001).

Conclusion: Measurement of the dead-space fraction at an early time of the diagnosis of the acute respiratory distress syndrome is a feasible, reliable in providing clinicians with more useful diagnostic and prognostic information early in the course of illness than the other physiological parameters. Measurement of the dead-space fraction could help clinical investigators to identify the patients who may benefit most from a particular tailoring of therapeutic intervention.
\end{abstract}

Keywords: ARDS, dead space fraction, mortality predictors. 


\section{Introduction}

The acute respiratory distress syndrome is an important cause of acute respiratory failure which carries a high mortality rate ${ }^{(1-5)}$.Variables that are independently associated with mortality are qualitative or not specific to abnormalities of pulmonary pathophysiology, such as age, nonpulmonary organ system dysfunction, sepsis and cirrhosis ${ }^{(4-7)}$. Although indexes of hypoxemia commonly measured for monitoring respiratory functions in the critical situations, such as the partial pressure of arterial oxygen $(\mathrm{PaO} 2)$, the fraction of inspired oxygen $(\mathrm{FiO} 2)$, and the ratio of $\mathrm{PaO} 2$ to $\mathrm{FiO} 2$, are thought to have considerable prognostic value ${ }^{(3,8)}$, recent studies strongly suggest that these variables are not independent mortality predictors when they were measured early in the course of the acute respiratory distress syndrome ${ }^{(4-6)}$

Physiologic dead-space fraction is the ratio of dead space to tidal volume [VD/VT]. It is the portion of tidal volume that does not participate in gas exchange and hence consists of expired gas without carbon dioxide. Historically, elevated VD/VT in patients with ARDS was thought to be a late-occurring phenomenon associated with the fibroproliferative stage of injury (1). However, newer evidence indicates that VD/VT is markedly elevated within the first $24 \mathrm{~h}$ of ARDS and is particularly elevated in non-survivors ${ }^{(2-8)}$ and its sustained elevation is associated with higher mortality ${ }^{(5,6)}$.

In this study, we aimed to study the physiological dead space fraction and other physiological parameters in mortality prediction for patients with ARDS.

\section{Patients and Methods \\ Patients}

The present study was conducted in the general ICU of Fayoum University Hospital and the respiratory ICU of El-Minia University Hospital from December 2013 to November 2015. The study included 30 criticallyill patients admitted to the ICU and met the diagnostic criteria of ARDS after having consent from the patients or their relatives. All ages and both sexes were included.

ARDS was diagnosed when subjects had to meet all 3 American-European Consensus Conference criteria: (1) $\mathrm{PaO} 2 / \mathrm{FIO} 2 \leq 300$, (2) bilateral infiltrates on chest radiograph during invasive mechanical ventilation, (3) the absence of evidence of elevated left atrial pressures) within the same 24 -h period ${ }^{(9)}$.

Patients with one or more of the following criteria were excluded from the study: clinical or radiological evidence of chronic lung disease, history of more than 60 pack-years of smoking, history or current treatment of hypertension, any primary cardiac disease or any systemic disease which can affect the heart e.g. autoimmune disorders, severe pulmonary hypertension with mean PAP > $40 \mathrm{~mm} \mathrm{Hg}$, or ventilator dependence, severe morbid obesity, diffuse alveolar hemorrhage from vasculitis, and patient survival less than $48 \mathrm{~h}$.

\section{All patients were thoroughly examined and subjected to the following:}

(1) Arterial blood gases (ABG) analysis on admission and regularly as needed for patient diagnosis and follow up.

(2) Chest imaging including plain $\mathrm{x}$ ray chest. CT chest was done for selected cases for tailoring patient management and to exclude other associated pulmonary comorbidities.

(3) Laboratory investigations including sputum examination and cultures, CBC (complete blood count), coagulation profile (PT, PC, INR and PTT), liver function tests, kidney function tests, blood sugar, serum electrolytes including $\mathrm{Na}, \mathrm{K}$ and calcium. Other laboratory investigations according to the patient condition were done both on admission and then as needed.

(4) Standard echo Doppler study.

- APACHE II score: All patients were evaluated according to the acute physiology and chronic health evaluation (APACHE II) scoring system at the time of admission ${ }^{(25)}$. The APACHE II score contains 
three components: age, acute physiologic score (APS), and chronic health. The total APACHE II score ranges from 0 to 71 and the higher scores imply a less favorable outcome. The acute physiologic score includes Glasgow Coma Score (GCS) as well as other physiologic variables. The 11 physiologic variables in the acute physiologic score contribute up to 4 points for each parameter. The patient's Glasgow Coma Score can add a further 15 points. Patients with severe organ system insufficiency and imuno-compromised patients receive 5 points for chronic health ${ }^{(10)}$.

\section{Lung Injury Score (LIS)}

The Lung Injury Score was used to assess the studied patients at the first 10 hours of diagnosis of ARDS. LIS assess 4 risk parameters: (1) chest X-ray evaluated for alveolar consolidation (2) PaO2/FIO2 (3) PEEP level in ventilated patients (4) respiratory compliance if known. Each parameter is given 0-4 score. The total ALI score ranges from 0 to 16 . A higher score implies a less favorable prognosis ${ }^{(11)}$.

\section{Measuring of airway resistance}

The airflow resistance during inspiration was determined by dividing the peak inspiratory flow rate (Vinsp) into the pressure which is needed to overcome the resistance to airflow (PIP-Pplat) ${ }^{(12)}$ :

$$
\text { Rinsp = PIP-Pplat / Vinsp }
$$

Where: PIP: peak inspiratory pressure, Pplat: plateau pressure, Rinsp: airway resistance during inspiration, Vinsp: peak inspiratory flow rate, ${ }^{(12)}$

\section{Measurement of compliance during MV}

Static compliance (Cst) is calculated as the ratio between VT and plateau pressure minus PEEP whether external applied or auto PEEP. The delivered tidal volume was corrected by subtracting the noncompressible volume of the tubing system that connects the patients to the mechanical ventilator. AutoPEEP was assessed by airway occlusion at end expiration and subtracting PEEP from the end-expiratory alveolar pressure $^{(12)}$.

Measurement of Dead-Space Fraction: For calculating the dead space, the mean expired carbon dioxide fraction was measured with a bedside metabolic monitor (Cap-ONE CO2 Sensor, TG-920; Nihon Kohden, Japan). The expired gas was measured for five minutes during which arterial blood gas measurement was made at the same time. The dead-space fraction was calculated with use of the Enghoff modification of the Bohr equation ${ }^{(13,14)}$ : dead-space fraction $=(\mathrm{PaCO} 2-\mathrm{PECO} 2) \div \mathrm{PaCO} 2$, where $\mathrm{PECO} 2$ is the partial pressure of carbon dioxide in mixed expired gas. The dead-space fraction is considered to be normal if it does not exceed $0.3^{(13,14)}$.

Patients were followed up until ICU discharge or demise. Type and duration of ventilatory support, development of complications during ICU stay, length of ICU stay and cause of death were recorded.

\section{Statistical analysis}

All statistical analyses were performed using SPSS statistics for Windows, version 17.0. Data were expressed as the mean \pm standard deviation for continuous variables and the number with percentage for categorical data. Comparisons between two categorical variables were made with chi-square. Continuous data were tested with Student's t-test. P values below 0.05 were taken to indicate statistical significance. All of the variables attaining a value $<0.05$ in the univariate analysis were included in the multiple logistic regression analysis models with a stepwise forward selection. 


\section{Results}

\section{Patient Characteristics}

The present study included 30 ICU admitted patients who met the all 3 American-European Consensus Conference criteria of ARDS. The main baseline patient characteristics and underlying conditions are listed in table 1. Male sex represented $60 \%$ of the patients and the mean age was $53.0 \pm 13.8$ years. The most frequent cause of ARDS was severe pneumonia (33.3\%), followed by sepsis (23.3\%). Sixty per cent of the patients were admitted for pure medical reasons whereas $40 \%$ were related to surgical scheduled causes.

The mean dead space fraction was $0.63 \pm 0.09$ (range: $0.51-0.73$ ). Absolute dead space was $6.1 \pm 1.8$ $\mathrm{ml} / \mathrm{kg}$ of ideal body weight (mean $\pm \mathrm{SD}$, range : 4.1-8.2)

APACHE II score, $\mathrm{PaO} 2: \mathrm{FiO} 2$ and ALI score were listed in table (1).

Table (1): Patient characteristics and the co-morbid conditions:

\begin{tabular}{|l|l|}
\hline $\begin{array}{l}\text { Patients (n: 30) } \\
\text { Males }\end{array}$ & $18(60 \%)$ \\
\hline $\begin{array}{l}\text { Age (years) (mean } \pm \text { SD) } \\
\text { Clinical disorder associated with the acute respiratory distress } \\
\text { syndrome (no. of patients \&\%) } \\
\text { Sepsis }\end{array}$ & $53.0 \pm 13.8$ \\
Aspiration & $7(23.3 \%)$ \\
Pneumonia & $3(10 \%)$ \\
Trauma, overdose, or idiopathic: & $10(33.3 \%)$ \\
\hline $\begin{array}{l}\text { APACHE II score (mean } \pm \text { SD) on admission } \\
\text { PaO2:FiO2 (mean } \pm \text { SD) on admission }\end{array}$ & $10(33.3 \%)$ \\
\hline Lung injury score (mean \pm SD) on admission & $27.4 \pm 8.2$ \\
\hline Reason for admission (no. of patients \&\%) & $176 \pm 32.2$ \\
Scheduled surgery & $10.2 \pm 1.9$ \\
Medical & $12(40 \%)$ \\
\hline Dead space fraction & $18(60 \%)$ \\
Absolute dead space (ml/kg of ideal body weight) & $0.63 \pm 0.09$ \\
\hline
\end{tabular}

\section{Mortality predictors in patients with ARDS}

The overall mortality rate was $60 \%$ among studied patients. Comparison between non-survivors and survivors was studied regarding patient characteristics and different parameters on admission including vital signs and laboratory findings.

The non-survivors had a significantly higher mean age than the survivors. They had also significantly higher APACHE II and ALI scores, higher heart rate, as well as lower systolic and diastolic blood pressure on admission than the survivor group. The non-survivors showed also significantly lower mean platelet count than survivors. The mean total leucocytic count, CRP, blood urea and serum creatinine were significantly higher in non-survivors compared to survivors. The duration of MV was significantly higher in nonsurvivors. 
Table (2): Comparison of different prognostic factors in surviving and non-surviving patients with ARDS

\begin{tabular}{|c|c|c|c|}
\hline & Non-survivors (n:18) & Survivors (n:12) & p-value \\
\hline Age (year) & $56.2 \pm 8.5$ & $51.5 \pm 12.9$ & 0.01 \\
\hline \multicolumn{4}{|l|}{ Vital signs on admission } \\
\hline HR (beats/m) & $125.4 \pm 22.1$ & $112.2 \pm 11.0$ & 0.09 \\
\hline Temperature ${ }^{\circ} \mathrm{C}$ & $38.2 \pm 1.1$ & $37.3 \pm 0.8$ & 0.5 \\
\hline SBP mmHg & $82.5 \pm 15.2$ & $93.2 \pm 16.1$ & 0.01 \\
\hline DBP $\mathrm{mmHg}$ & $47.9 \pm 8.6$ & $51.9 \pm 12.1$ & 0.01 \\
\hline APACHE II score on admission & $27.1 \pm 5.9$ & $16.5 \pm 2.9$ & 0.001 \\
\hline ALI score on diagnosis & $12.7 \pm 2.2$ & $8.3 \pm 3.2$ & 0.005 \\
\hline \multicolumn{4}{|l|}{ Lab investigation on diagnosis } \\
\hline Hemoglobin $\mathrm{g} / \mathrm{dl}$ & $11.1 \pm 2.3$ & $10.2 \pm 2.2$ & 0.1 \\
\hline Total Leukocyte count $\left(\times 10^{9} / \mathrm{L}\right)$ & $14.4 \pm 5.4$ & $10.4 \pm 2.1$ & 0.01 \\
\hline Platelets $\left(\times 10^{9} / \mathrm{L}\right)$ & $165 \pm 57$ & $265 \pm 38$ & 0.01 \\
\hline CRP mg/l & $65 \pm 21$ & $45 \pm 11$ & 0.01 \\
\hline Serum sodium $(\mathrm{mmol} / \mathrm{l})$ & $139.5 \pm 2.7$ & $138.2 \pm 1.6$ & 0.2 \\
\hline Serum potassium $(\mathrm{mmol} / \mathrm{l})$ & $3.7 \pm 1.2$ & $3.9 \pm 1.1$ & 0.6 \\
\hline Serum urea $(\mathrm{mg} / \mathrm{dl})$ & $42 \pm 12$ & $28 \pm 5.5$ & 0.02 \\
\hline Serum creatinine $(\mathrm{mg} / \mathrm{dl})$ & $2.8 \pm 1.2$ & $1.1 \pm 1.5$ & 0.01 \\
\hline Duration MV (day) & $13.2 \pm 6.3$ & $8.1 \pm 2.9$ & 0.01 \\
\hline Length of ICU stay (day) & $13.4 \pm 5.1$ & $14.3 \pm 6.2$ & 0.5 \\
\hline
\end{tabular}

\section{Prognostic factors of DSF and other lung mechanics in ARDS}

The mean dead-space fraction was significantly higher in non-survivors than in survivors $(0.67 \pm 0.08$ vs. $0.57 \pm 0.09, \mathrm{P}<0.001$ ) (table 3 ). The risk of death increased as the dead-space fraction increased. In the multiple-regression analysis, the dead-space fraction was also independently associated with an increased mortality risk. For every increase of 0.05 in the dead-space fraction, the risk of death increased by 65 percent (odds ratio, 1.65; 95 percent confidence interval, 1.25 - 1.79; $\mathrm{P}=0.001$ ) (table 4). The mean positive end-expiratory pressure was similar among patients who died and those who survived (10.2 \pm 3.1 and $10.0 \pm 3.5 \mathrm{~cm}$ of water, respectively).

Both static and dynamic compliance as well as $\mathrm{PaO}_{2} / \mathrm{FiO}_{2}$ were independently associated with an increased risk of death. The odds of death increased as the APACHE II and Lung injury scores increased and as compliance and $\mathrm{PaO}_{2} / \mathrm{FiO}_{2}$ decreased. The positive end expiratory pressure was not associated with an increased risk of death (odds ratio, 1.05; 95 percent confidence interval, 0.95 to $1.19 ; \mathrm{P}=0.23$ ), and also not with the time from diagnosis to the measurement of the dead-space fraction (odds ratio, 0.99; 95 percent confidence interval, 0.96 to $1.04 ; \mathrm{P}=0.76$ ) (Table 4).

Table (3): Comparison of DSF, $\mathrm{PaO}_{2} / \mathrm{FiO}_{2}$ and lung mechanics between surviving and non-surviving patients with ARDS

\begin{tabular}{|l|c|c|c|}
\hline \multicolumn{1}{|c|}{ Parameters studied } & Non-survivors (n:18) & Survivors (n:12) & p-value \\
\hline $\mathrm{DSF}$ & $0.67 \pm 0.08$ & $0.57 \pm 0.09$ & 0.001 \\
$\mathrm{PaO}_{2} / \mathrm{FiO}_{2}(\mathrm{mmHg})$ & $158 \pm 57$ & $192 \pm 48$ & 0.04 \\
\hline $\mathrm{Cst}(\mathrm{ml} / \mathrm{cmH} 2 \mathrm{O})$ & $31.03 \pm 11.78$ & $35.63 \pm 13.41$ & 0.03 \\
$\mathrm{Cdyn}(\mathrm{ml} / \mathrm{cmH} 2 \mathrm{O})$ & $16.62 \pm 7.57$ & $22.47 \pm 8.21$ & 0.05 \\
\hline $\mathrm{Raw}(\mathrm{cmH} 2 \mathrm{O} / \mathrm{l} / \mathrm{s}$ & $11.17 \pm 6.01$ & $10.99 \pm 18.7$ & 0.11 \\
\hline $\mathrm{ETCO} 2(\mathrm{mmHg})$ & $54.69 \pm 23.51$ & $53.39 \pm 19.49$ & 0.21 \\
\hline
\end{tabular}

DSF : dead space fraction , Cdyn: dynamic compliance; Cst, static compliance; Raw: airway resisirance;

ETCO2: end-tidal carbon dioxide. 
Table (4): Odds Ratios for variables independently associated with increased risk of death

\begin{tabular}{|c|c|c|c|}
\hline Parameters studied & Odds ratio & $\begin{array}{l}\text { 95\% confidence } \\
\text { interval }\end{array}$ & p-value \\
\hline DSF (per 0.05 increase) & 1.75 & $1.27-1.82$ & 0.001 \\
\hline APACHE II (per 5 point increase) & 1.28 & $1.15-1.55$ & 0.04 \\
\hline LIS (per 1 point increase) & 1.26 & $1.15-1.54$ & 0.03 \\
\hline $\begin{array}{l}\text { Cst }(\mathrm{ml} / \mathrm{cmH} 2 \mathrm{O}) \\
\text { (per decrease of } 1 \mathrm{ml} / \mathrm{cm} \text { of water) }\end{array}$ & 1.35 & $1.22-1.58$ & 0.04 \\
\hline $\begin{array}{l}\text { Cdyn }(\mathrm{ml} / \mathrm{cmH} 2 \mathrm{O}) \\
\text { (per decrease of } 1 \mathrm{ml} / \mathrm{cm} \text { of water) }\end{array}$ & 1.28 & $1.19-1.45$ & 0.05 \\
\hline $\begin{array}{l}\mathrm{PaO}_{2} / \mathrm{FiO}_{2} \\
\text { (per decrease of } 10 \mathrm{ml} / \mathrm{cm} \text { of water) }\end{array}$ & 1.32 & $1.15-1.62$ & 0.01 \\
\hline $\begin{array}{l}\text { PEEP } \\
\text { (per increase of } 1 \mathrm{ml} / \mathrm{cm} \text { of water) }\end{array}$ & 1.05 & $0.95-1.19$ & 0.23 \\
\hline
\end{tabular}

DSF : dead space fraction , Cdyn: dynamic compliance; Cst, static compliance; Raw: airway resisirance; ETCO2: end-tidal carbon dioxide, LIS : lung injury score, APACHE II: acute physiology and chronic health evaluation PEEP : positive endexpiratory pressure

\section{Correlation between DSF and APACHE II and LIS}

Correlation of DSF on admission and APACHE II and LIS were tested in all studied patients. There was a statistically significant positive correlation between DSF and APACHE II score ( $r=0.53, \mathrm{P}$ value 0.001$)$ as well as LIS ( $\mathrm{r}=0.47$, $\mathrm{P}$ value 0.01$)$.

\section{Correlation between DSF and other physiological parameters}

DSF on admission had a significant negative correlation with the static compliance $(\mathrm{r}=-0.43, \mathrm{P}$ value 0.01 ), dynamic compliance $\left(\mathrm{r}=-0.47, \mathrm{P}\right.$ value 0.01 ) and $\mathrm{PaO}_{2} / \mathrm{FiO}_{2}(\mathrm{r}=0.73, \mathrm{P}$ value 0.001$)$.

The dead-space fraction was found to be weakly associated with the level of positive end-expiratory pressure $(\mathrm{r}=0.24, \mathrm{P}=0.01)$ and the level of peak inspiratory pressure $(\mathrm{r}=0.23, \mathrm{P}<0.01)$, and it was not associated with the time from the diagnosis of the ARDS to the measurement of the dead-space fraction $(\mathrm{r}=$ ‘0.05, $\mathrm{P}=0.48)$.

\section{Discussion}

ARDS is characterized by a non-cardiogenic pulmonary edema with significant impairment of gas exchange. The increases in the right-to-left intrapulmonary shunt and the low ventilation-to-perfusion ratio lead to hypoxemia, whereas the increase in pulmonary dead space reduces CO2 removal ${ }^{[15,16]}$. The increase in pulmonary dead space is due mainly to alterations in pulmonary blood flow distribution that results from vascular obstruction, regional overdistension of ventilated alveoli induced by positive end-expiratory pressure (PEEP) as well as by the reduction in cardiac output ${ }^{[17-19]}$.

In this study, we aimed to study the physiological dead space fraction and other lung mechanics in mortality prediction for patients with ARDS.

The present study showed that the mean dead space fraction was $0.63 \pm 0.09$ (range: $0.51-0.73$ ). Absolute dead space was $6.1 \pm 1.8 \mathrm{ml} / \mathrm{kg}$ of ideal body weight (mean $\pm \mathrm{SD}$, range : 4.1-8.2). The mean dead-space fraction was significantly higher in non-survived patients $(0.67 \pm 0.08$ vs. $0.57 \pm 0.09, \mathrm{P}<0.001)$. The risk of death increased as the dead-space fraction increased. The dead-space fraction was also independently associated with an increased risk of death in the multiple-regression analysis. For every increase of 0.05 in the dead-space fraction, the odds of death increased by 65 percent.

This comes in accordance with a recent study ${ }^{(13)}$ who tested the association between pulmonary dead-space fraction and mortality in subjects with ARDS according to Berlin definition $(\mathrm{PaO} 2 / \mathrm{FIO} 2<300 \mathrm{~mm} \mathrm{Hg}$; PEEP > $5 \mathrm{cmH} 2 \mathrm{O}$ ) in 126 patients and found that non-survivors had higher VD/VT compared with 
survivors $\left(0.62 \_0.11\right.$ vs $0.56 \_0.11$, respectively, and the association between VD/VT and mortality was significant on study day 1 .

Our results also comes in agreement with another study (14) in which DSF was tested in 179 subjects with ARDS and showed increased DSF in non-survivors compared to survivors $(0.63 \pm 0.10$ vs. $0.54 \pm 0.09$, $\mathrm{P}<0.001$ ). they also showed that the DSF was an independent risk factor for death: for every 0.05 increase, the odds of death increased by 45 percent .

The present results revealed that DSF was negatively correlated with both static and dynamic compliance as well as $\mathrm{PaO}_{2} / \mathrm{FiO}_{2}$ whereas a weak positive correlation was found with PEEP as well as peak inspiratory pressure. DSF showed a positive correlation with both APACHE II and lung injury scores on admission This comes in agreement with other recent studies ${ }^{(20-26)}$

The present study tested other physiological parameters as predictors of mortality. It was found that both static and dynamic compliance as well as $\mathrm{PaO}_{2} / \mathrm{FiO}_{2}$ were independently associated with an increased risk of death. However, change of DSF was comparably associated of higher mortality risk than static and dynamic compliance and $\mathrm{PaO}_{2} / \mathrm{FiO}_{2}$. On the other hand, PEEP was not associated with an increased risk of death. This comes in partial agreement with Kallet et al ${ }^{(13)}$ and Nukton et al ${ }^{(14)}$ studies. On the other hand, other studies revealed that respiratory compliance was not independently predictive when it was measured early in the acute respiratory distress syndrome ${ }^{(27-29)}$. However, From a mechanical perspective, respiratory compliance is expected to be more deteriorated in more severely affected patients with less favorable outcome as patients with less compliant lungs may have more severe pulmonary edema and reduced concentrations of functional surfactant ${ }^{(14)}$.

It is concluded that, bedside measurement of the dead-space fraction at the time of the diagnosis of the acute respiratory distress syndrome is a feasible, reliable in providing clinicians with useful diagnostic prognostic information early in the course of illness than the other physiological parameters. Measurement of the deadspace fraction could help clinical investigators identify the patients who may benefit most from a particular therapeutic intervention. We recommend the clinical use of the dead-space fraction in future clinical trials to evaluate the benefit of tailoring therapies in critically ill patients with ARDS.

\section{References}

1. Petty TL, Ashbaugh DG. The adult respiratory distress syndrome: clinical features, factors influencing prognosis and principles of management. Chest 1971;60:233-9.

2. The Acute Respiratory Distress Syndrome Network. Ventilation with lower tidal volumes as compared with traditional tidal volumes for acute lung injury and the acute respiratory distress syndrome. N Engl J Med 2000;342:1301-8.

3. Sloane PJ, Gee MH, Gottlieb JE, et al. A multicenter registry of patients with acute respiratory distress syndrome: physiology and outcome. Am Rev Respir Dis 1992;146:419-26.

4. Doyle RL, Szaflarski N, Modin GW, Wiener-Kronish JP, Matthay MA. Identification of patients with acute lung injury: predictors of mortality. Am J Respir Crit Care Med 1995;152:1818-24.

5. Zilberberg MD, Epstein SK. Acute lung injury in the medical ICU: comorbid conditions, age etiology, and hospital outcome. Am J Respir Crit Care Med 1998;157:1159-64.

6. Guo F, Chen J, Liu S, Yang C, Yang Y. Dead-space fraction changes during positive end-expiratory pressure titration following lung recruitment in acute respiratory distress syndrome patients. Respir Care 2012;57(10):1578-1585.

7. The ARDS Definition Taskforce. Acute respiratory distress syndrome: the Berlin definition. JAMA 2012;307(23): 2526-2533. 
8. Ong T, McClintock DE, Kallet RH, Ware LB, Matthay MA, Liu KD. Ratio of angiopoietin-2 to angiopoeitin-1 as a predictor of mortality in acute lung injury patients. Crit Care Med 2010;38(9):17.

9. Bernard GR, Artigas A, Brigham KL, et al. The American-European Consensus Conference on ARDS: definitions, mechanisms, relevant outcomes, and clinical trial coordination. Am J Respir Crit Care Med 1994; 149:818-24.

10. Zimmerman J, Kramer A, McNair A et al. Acute Physiology and Chronic Health Evaluation (APACHE). : ICU length of stay benchmarks for today's critically ill patients. Critical Care Med. 2006; 34:2517-2529.

11. Murray JF, Matthay MA, Luce JM, Flick MR: An expanded definition of the adult respiratory distress syndrome. Am Rev Respir Dis 1988,138(3):720-723. 10.1164/ajrccm/138.3.720

12. Tobin M, Vav de Graaff WB. Monitoring of lung mechanics and work of breathing, principles and practice of mechanical ventilation. Edited by Tobin MJ. Principles and Practice of Mechanical Ventilation. New York: McGraw-Hill; 1994. p. 967-1003.

13. Kallet RH, FAARC RRT, Zhuo H , D Liu K,Calfee CS, and Matthay MA: The Association Between Physiologic Dead-Space Fraction and Mortality in Subjects With ARDS Enrolled in a Prospective Multi-Center Clinical Trial. Respiratory Care 2014 Nov VOL 59 No 11

14. Nuckton T, Alonso J, Kallet R, Daniel B, Pittet JF, Eisner MD, MatthayMA: Pulmonary dead space fraction as a risk factor for death in the acute respiratory distress syndrome. N Engl J Med, Vol. 346, No. 17. April 25, 2002.

15. Dantzker DR, Brook CJ, Dehart P, Lynch JP, Weg JG: Ventilation-perfusion distributions in the adult respiratory distress syndrome. Am Rev Respir Dis 1979, 120:1039-1052.

16. Ralph DD, Robertson HT, Weaver LJ, Hlastala MP, Carrico CJ, Hudson LD: Distribution of ventilation and perfusion during positive end-expiratory pressure in the adult respiratory distress syndrome. Am Rev Respir Dis 1985, 131:54-60.

17. Coff ey RL, Albert RK, Robertson HT: Mechanisms of physiological dead space response to PEEP after acute oleic acid lung injury. J Appl Physiol 1983, 55:1550-1557.

18. Suwa K, Hedley-Whyte J, Bendixen HH: Circulation and physiologic dead space changes on controlling the ventilation of dogs. J Appl Physiol 1966, 21:1855-1859.

19. Tomashefski JF Jr., Davies P, Boggis C, Greene R, Zapol WM, Reid LM: The pulmonary vascular lesions of the adult respiratory distress syndrome. Am J Pathol 1983, 112:112-126.

20. Nuckton T, Alonso J, Kallet R, Daniel B, Pittet JP, Eisner M, Matthay MA. Early elevation in deadspace ventilation is associated with mortality risk in patients with acute respiratory distress syndrome. N Engl J Med 2002;346(17):1281-1286.

21. Lucangelo U, Bernabe F, Vatua S, Degrassi G, Villagra A, Fernandez R, Romero PV, Saura P, Borelli M, Blanch L. Prognostic value of different dead space indices in mechanically ventilated patients with acute lung injury. Chest 2008;133(1):62-71.

22. Guo F, Chen J, Liu S, Yang C, Yang Y. Dead-space fraction changes during positive end-expiratory pressure titration following lung recruitment in acute respiratory distress syndrome patients. Respir Care 2012;57(10):1578-1585.

23. Kallet RH, Daniel B, Garcia O, Matthay MA. Accuracy of physiologic dead space measurements in patients with acute respiratory distress syndrome using volumetric capnography: comparison with the metabolic monitor method. Respir Care 2005;50(4):462-467. 
24. Siddiki H, Kojicic M, Li G, Yilmaz M, Thompson TB, Hubmayr RD, Gajic O. Bedside quantification of dead-space fraction using routine clinical data in patients with acute lung injury: secondary analysis of two prospective trials. Crit Care 2010;14(4):R141.

25. Matthay MA, Kallet RH. Prognostic value of pulmonary dead-space fraction in patients with the acute respiratory distress syndrome. Crit Care 2011;15(5):R185.

26. Charron C Repesse X, Bouferrache K, Bodson I, Castro S, Page B, et al. A PaCO2 and alveolar dead space are more relevant than $\mathrm{PaO} 2 / \mathrm{FiO} 2$ in monitoring the respiratory response to prone position and acute respiratory distress syndrome: a physiologic study. Crit Care 2011;15(5):R175.

27. Doyle RL, Szaflarski N, Modin GW, Wiener-Kronish JP, Matthay MA. Identification of patients with acute lung injury: predictors of mortality.Am J Respir Crit Care Med 1995;152:1818-24.

28. Zilberberg MD, Epstein SK. Acute lung injury in the medical ICU: comorbid conditions, age etiology, and hospital outcome. Am J Respir Crit Care Med 1998;157:1159-64.

29. Monchi M, Bellenfant F, Cariou A, et al. Early predictive factors of survival in the acute respiratory distress syndrome: a multivariate analysis. Am J Respir Crit Care Med 1998;158:1076-81. 